\title{
SOBRE O CONCEITO DE POLÍTICAS PÚBLICAS
}

\author{
ON THE CONCEPT OF PUBLIC POLICIES
}

Josué Mastrodi

Professor da Pontifícia Universidade Católica de Campinas. Centro de Ciências Humanas e Sociais Aplicadas. Programa de Pós-Gradução Stricto Sensu em Direito. Doutor em Direito pela Universidade de São Paulo.

E-mail: mastrodi@puc-campinas.edu.br

\section{Fernanda Carolina de Araujo Ifanger}

Professora da Pontifícia Universidade Católica de Campinas. Centro de Ciências Humanas e Sociais Aplicadas. Programa de Pós-Gradução Stricto Sensu em Direito. Doutora em Direito pela Universidade de São Paulo.

E-mail: fernanda.ifanger@puc-campinas.edu.br

Recebido em: 22/08/2019

Aprovado em: 27/04/2020

RESUMO: A expressão "políticas públicas" tem sido usada, em profusão, para se referir a um certo tipo de ação estatal eficaz para promover e garantir quaisquer direitos e, no limite, um remédio capaz de resolver todas (ou quase todas) as demandas da sociedade. Aparentemente, políticas públicas têm sido relacionadas quase que exclusivamente aos direitos sociais, já que os direitos individuais teriam a qualidade de serem garantidos diretamente pela lei, sem necessidade de recursos públicos direcionados à sua promoção. Em que pese haver excelentes autores que tratam há tempos do tema, apresentamos contribuição para a construção do conceito de políticas públicas no campo da teoria geral do direito, contextualizando sua concepção no âmbito do Estado liberal, de modo que, em seu sentido original, elas não tinham por objeto, nem por finalidade imediata, a promoção ou proteção de direitos, e que, no âmbito do Estado de bem-estar social, direitos universalizados não deveriam ser garantidos por políticas públicas que têm prazo para terminar.

Palavras-chave: Políticas públicas. Conceito funcionalista de políticas públicas. Contexto histórico das políticas públicas. Direitos no Estado liberal. Direitos no Estado de bem-estar social.

\begin{abstract}
The term "public policy" has been used in abundance to refer to a certain type of effective governmental action to promote and guarantee any rights and, to the limit, a remedy capable of solving all (or almost all) the problems in society. It seems that public policies have been strongly connected to social rights, since individual rights would have the quality of being guaranteed directly by law, without the need of public resources aimed at their promotion. Although there are excellent authors who have consistently dealt with the subject, we present this contribution to the construction of the concept of public policies in accordance with general theory

\footnotetext{
* A elaboração deste trabalho contou com o apoio das contribuições dos mestrandos Paula Gomes da Conceição, Renan Alarcon Rossi, Suzana Maria Loureiro Silveira e João Paulo Ghiraldelli Dal Poggetto, pesquisadores vinculados à Linha de Pesquisa Direitos Humanos e Políticas Públicas da PUC-Campinas. Os autores aproveitam para agradecer a avaliação dos(as) Sr(a)s. pareceristas indicados pelo Conselho Editorial da Revista de Direito Brasileira, cujas considerações contribuíram substancialmente para a edição final deste trabalho, ora publicado.
} 
of Law, understanding it in the context of the Liberal State, in such a way that, in their specific sense, public policies do neither have the object nor the immediate purpose of promoting or protecting rights; and that, in the context of the Welfare State, universal rights should not be promoted by public policies, that have term to be finished.

Keywords: Public policies. Functionalist concept of public policies. Historical context of public policies. Rights in the Liberal State. Rights in the Welfare State.

SUMÁRIO: Introdução; 1. Da estrutura à função; 2. Políticas públicas servem à promoção de objetivos, não de direitos; 3. Não há direitos sociais no Estado liberal, mas há políticas públicas; 4. Há direitos sociais no Brasil: as ações que os promovem são políticas públicas? 5. Compreensão de políticas públicas no direito interno a partir de sua compreensão no direito internacional; Considerações finais; Referências.

\section{INTRODUÇÃO}

O presente artigo tem como proposta, a partir do Direito e dentro de um diálogo interdisciplinar, a análise e a discussão sobre as políticas públicas numa perspectiva descritivonormativa. A abordagem parte da premissa pela qual a expressão "políticas públicas" tem sido apresentada como a estruturação de uma ação estatal capaz de resolver (quase) todos os problemas sociais, um remédio eficaz para promover e garantir quaisquer direitos, em especial os direitos sociais ou de segunda dimensão.

Não obstante haver expressivos autores nacionais (SOUZA, 2006; FREY, 2000; COMPARATO; 1998, BUCCI, 1997) e estrangeiros (KINGDON, 2014; LÖWI, 1972) que tratam deste tema há tempos e de modo muito consistente, parece-nos relevante apontar algumas considerações no que respeita a conceituar políticas públicas. Tais apontamentos nos parecem importantes tanto para entender políticas públicas no cenário brasileiro quanto para compreender o conceito de políticas públicas no campo da teoria geral do Direito. O tema se faz relevante, ainda, tanto porque são vários os programas de pós-graduação em Direito e Interdisciplinares que se debruçam sobre ele, quanto pela falta de textos de referência sobre o conceito de políticas públicas em revistas qualificadas nos últimos quatro ou cinco anos. ${ }^{1}$ Ou seja, não obstante haver importante produção científica sobre o tema como um topo, não há precisão sobre o que políticas públicas significam. $^{2}$

\footnotetext{
${ }^{1}$ Em rápida pesquisa pela palavra-chave "políticas públicas" nas revistas de Direito Público e Interdisciplinares indexadas com Qualis A1, A2 ou B1, ou ainda na plataforma Scielo.br, não há artigos sobre a definição de políticas públicas, em que pese haver boa quantidade deles que, de alguma forma, usam as políticas públicas como meio para tratar de outros temas; nos artigos analisados, o aprofundamento de seu conceito não era seu objeto central de pesquisa, sendo utilizada uma definição simplificada visando apenas a sua aplicação instrumental.

2 À guisa de exemplo, a Revista de Direito Brasileira já publicou expressiva quantidade de artigos que possuem a expressão "políticas públicas" (ou "política pública") no título ou como uma das palavras-chave de indexação. Em nenhum deles, contudo, houve intenção dos autores quanto a definir ou contextualizar o sentido do que se possa entender por políticas públicas: Moura (2019) trata de controle de políticas públicas, e até define o que entende por controle, que é seu efetivo objeto de pesquisa, mas não precisa o que seriam as políticas públicas sujeitas ao controle; Padin e Oliveira (2018) afirmam que o Sistema Único de Saúde é uma das maiores políticas públicas do Brasil (2018, p. 430) e apresentam o estado da arte do que se entende por políticas públicas no Brasil a partir de outros autores, afirmando falta de consenso e até a existência de alguma arbitrariedade nas várias definições apresentadas (2018, p. 431-432); Kim e Tommasiello (2018) diferenciam políticas públicas de ações afirmativas, apontando estas como uma espécie daquelas que, por serem apresentadas como gênero, não foram precisadas; Leitão et al (2017, p. 311) afirmam que deve haver políticas públicas de inclusão social e que devem gerar riqueza em vez de simplesmente distribuí-la (2017, p. 322), mas sem preocupação em definir políticas públicas de inclusão ou de geração de riqueza; Pompeu et al (2014, p. 240) afirmam que políticas públicas são necessárias para o poder Executivo cumprir promessas
} Revista de Direito Brasileira | Florianópolis, SC | v. 24 | n. 9 | p.05-18 |Set./Dez. 2019 
Em termos de metodologia e procedimentos utilizados para o desenvolvimento deste estudo, partiu-se de um processo dialógico de construção de conhecimento com desenvolvimento das leituras e discussões no âmbito do Programa de Pós Graduação em Direito da Pontifícia Universidade Católica de Campinas, ao qual seus autores estão vinculados.

Para fins da apresentação da problemática da pesquisa ora apresentada, este artigo tem como objetivo principal formular algumas pontuações sobre a compreensão e o significado daquilo que se convencionou chamar políticas públicas. Em linhas gerais, o artigo apontará resultados obtidos, de forma dogmática, acerca dos limites conceituais desta temática.

A realização do presente estudo se deu tendo por base a compreensão de que deve haver diálogo e interdisciplinariedade entre o Direito e as demais ciências humanas para que se produza ciência (NOBRE et al, 2005, p. 24). A partir daí, questionou-se a compreensão corrente de políticas públicas como promotoras de direitos, especialmente os sociais, especialmente porque as políticas públicas se originaram em um país em que não se reconhecem direitos sociais como direitos fundamentais. Nossa hipótese é que políticas públicas devem significar algo mais preciso do que qualquer ação realizada pelo Estado. Por meio de revisão bibliográfica, esperamos confirmar a hipótese formulada, para compreender as políticas públicas como ações materializadoras de objetivos do Estado, a partir das quais a promoção de direitos é uma consequência desejada, mas não sua finalidade primária.

Por este artigo, pretendemos apresentar algumas considerações que têm sido levantadas sobre políticas públicas na Linha de Pesquisa Direitos Humanos e Políticas Públicas de nosso Programa de Pós-Graduação em Direito, e contribuir para o aprofundamento desse conceito, cuja aplicação se apresenta cada vez mais intensa tanto nas discussões acadêmicas quanto no planejamento e gerenciamento dos Administradores Públicos.

Parece-nos que algumas considerações que foram suscitadas por Ribeiro e Anjos (2011, p. 294) sobre políticas públicas são sobremodo acertadas, porquanto entenderam por bem relacioná-las diretamente ao conceito de desenvolvimento, e não ao de direitos ou de direitos sociais. Estes autores entendem que as políticas públicas são fundamentais para promoção de direitos humanos, mas a partir da promoção do desenvolvimento, tanto que, para eles, "maior desenvolvimento e industrialização correspondem quase sempre a um maior reconhecimento de garantias sociais ... gerando, assim, maior aproximação e equilíbrio entre crescimento e proteção social” (RIBEIRO e ANJOS, 2011, p. 308).

Procuramos seguir exatamente neste mesmo sentido, de modo a dissociar as políticas públicas de um dever ou finalidade de promoção necessária de direitos sociais. Não se pretende, com isto, reduzir a proteção normativa aos direitos sociais. Ao contrário, parece-nos que, ao definirmos políticas públicas como algo que não serve à garantia direta e imediata de direitos sociais, estes podem ser mais bem assegurados pelos meios adequados à sua universalização.

Os resultados aqui apresentados, derivados de pesquisas bibliográficas, não são definitivos, haja vista que o tema, interdisciplinar por natureza, impede que as políticas públicas sejam constatadas objetivamente a partir de alguma característica exclusiva e indisputável. Tratam, contudo, de contribuições de nosso Programa de Pós-Graduação que, esperamos, sejam úteis para o debate e a busca por uma compreensão cada vez mais precisa de um conceito que é, sem dúvida, socialmente relevante tanto nas ciências sociais aplicadas quanto, para fins de impacto social, na realidade de governos e de organizações internacionais.

Este artigo está estruturado em cinco seções. Na primeira, em conformação ao estado da arte das teorias sobre políticas públicas, abordaremos a necessidade de se compreenderem as políticas públicas segundo sua função e não segundo suas propriedades objetivas.

Na segunda, buscamos explicar por que políticas públicas não se prestam diretamente a promover direitos, embora estes sejam indiretamente promovidos por políticas públicas que visam, 
isto sim, a propiciar os objetivos do Estado ou, no cenário internacional, os objetivos propostos em tratados e convenções internacionais.

A terceira seção vem em seguida para afirmar que políticas públicas podem servir para melhorar a condição tanto de direitos sociais quanto de direitos individuais, não havendo relação necessária entre elas e os direitos sociais, e que os custos estatais, inerentes a qualquer política pública, não servem para distinguir direitos individuais de sociais.

Na quarta seção, mostramos que direitos sociais, no âmbito do Estado de bem-estar social, não devem ser garantidos por meio de políticas públicas, e que, por este mesmo motivo, os serviços públicos de universalização de direitos sociais, por sua característica de continuidade (ou seja, sua interrupção deve ser entendida como vedada), não podem ser adequadamente compreendidos como políticas públicas.

Na quinta seção, desenvolvemos algumas considerações sobre o dever constitucional de promoção de direitos sociais, embora este dever não deva ser compreendido como política pública stricto sensu.

Em suas considerações finais, o artigo defende que as políticas públicas servem à função de materializar os objetivos do Estado e não de promover direitos sociais, já que estes devem ser buscados por meio de ações estatais contínuas e ininterruptas, diversamente das políticas públicas que, necessariamente, têm um começo, um meio e um fim.

\section{DA ESTRUTURA À FUNÇÃO}

A teoria do Direito Público em geral, e a do Direito Administrativo em particular, de há muito deixou de buscar a compreensão do direito a partir de sua estrutura, para entendê-lo segundo sua função. Norberto Bobbio (2007) talvez tenha sido o primeiro filósofo do direito a apontar para a importância de compreender o direito segundo a função que este exerce na sociedade, em vez de buscar a essência (se é que isso existe) da normatividade jurídica. Se não funcionar, não adianta. Essa visão funcionalista tem sido aplicada para compreender o direito administrativo ao menos desde a década de 1970. Não importa quem é o sujeito ativo do direito administrativo, tampouco qual é o seu objeto, mas compreender se essa estrutura -pública, privada ou mista- funciona visando a promover o interesse público acima dos interesses privados.

De igual forma, a definição de políticas públicas tem sido compreendida em seu sentido funcional: tem que funcionar, não havendo muita discussão sobre o que seria uma política pública, mas se ela serve a um determinado propósito. Maria Paula Dallari Bucci (1997, p. 91), justamente nesse sentido, considera que as políticas públicas são úteis para analisar as funções do Estado, de modo que, aqui, pretendemos entender a função da política pública. ${ }^{3}$

Mas o que é que precisa funcionar, no âmbito do Estado, para isso ser entendido como políticas públicas? Se qualquer ação do Estado funcionar para atingimento de qualquer finalidade pública, isso poderia ser entendido como política pública? Thomas Dye (apud SOUZA, 2006, p. 24), no limite, já afirmou que política pública seria tudo o que o Estado escolhe fazer ou não fazer. Ainda que essa definição seja muito simplista, ela não é, de modo algum, funcionalista. Se a ação estatal realizada servir apenas para movimentar a burocracia estatal, isso foi feito para o cumprimento de algum interesse público secundário, mas ninguém concordaria que essa ação seria algum tipo de política pública.

Celina Souza (2006, p. 26) sintetiza o campo da política pública como a área do conhecimento que busca "colocar o governo em ação", algo que é corroborado por Gobert e Muller

\footnotetext{
${ }^{3}$ Não há problema algum em se pautar a compreensão de política pública segundo esse viés funcionalista. Até a propriedade privada, direito fundamental de primeira dimensão, deve ser compreendido segundo sua função social.
}

Revista de Direito Brasileira | Florianópolis, SC | v. 24 | n. 9 | p.05-18 |Set./Dez. 2019 
$(1987)^{4}$ e por Viana (1996, p. 5), mas essa noção é muito inicial, tanto que Souza desenvolve o conceito a partir de uma compreensão institucional (ou melhor, neo-institucionalista) da política pública como um campo, ou seja, como uma área de estudo em que políticas públicas são produzidas e implementadas. Não obstante, isso não confere às políticas públicas uma definição nem ontológica, nem funcionalista. E do ponto de vista da teoria do direito, tampouco fornece uma definição apropriável em temos normativos.

Deveras, do ponto de vista ontológico, a descrição do que uma política pública seja não é nem um pouco útil. Com características ora normativas, ora descritivas, ora de natureza científica, ora política, não há qualquer consenso sobre o que, de fato, deva ser entendido como políticas públicas. Estas, assim, em termos pragmáticos, passaram a se referir a uma série de atos, programas ou estruturas que funcionam para a consecução de um determinado fim.

Daí a abordagem metodológica sobre políticas públicas se dar, ao menos desde Theodore Löwi (1972), em função dos fins a que se destinam, fins estes que permitiram que Löwi classificasse as políticas públicas, mas não que as definisse. Daí, também, a compreensão de políticas públicas sempre de modo interdisciplinar, ora dando-se ênfase a uma de suas características, ora a outras, mas sempre as concertando de modo a promover a finalidade nela prevista.

\section{POLÍTICAS PÚBLICAS SERVEM À PROMOÇÃO DE OBJETIVOS, NÃO DE DIREITOS}

Em termos funcionais, portanto, parte-se da ideia de que políticas públicas servem para promover alguma coisa importante. Como nada é mais importante ou relevante do que direitos humanos, estes são comumente entendidos como o objeto (ou melhor, como a finalidade) de qualquer política pública.

Considerando que direitos humanos compõem uma das principais pautas das Nações Unidas, o Direito Internacional dos Direitos Humanos tende a ser promovido, no âmbito interno dos Estados, pela atuação direta ou indireta destes, visando, por ações estruturadas e concertadas, ao aprimoramento, à promoção e/ou à garantia de algum direito. Essas ações, portanto, são entendidas como políticas públicas, que são criadas e que existem em função dos direitos que visam a proteger. A este respeito, cabem referências à Agenda $2030^{5}$ e os Objetivos do Desenvolvimento Sustentável, à Nova Agenda Urbana de 2016 da ONU-Habitat, ${ }^{6}$ à Declaração das Nações Unidas sobre Direito ao Desenvolvimento de $1986 .^{7}$

Nossa posição contraria esse entendimento. Conforme esperamos demonstrar, direitos não são o objeto nem a finalidade imediata das políticas públicas. Mais acertado, contudo, parece-nos, é considerar as políticas públicas em função dos objetivos que o Estado, por determinação constitucional ou legal, tem o dever de tutelar.

Conforme consta do artigo $3^{\circ}$ da Constituição da República de 1988, o Estado brasileiro possui certos objetivos fundamentais que, em regra, devem ser promovidos por uma série de ações concertadas.

\footnotetext{
${ }^{4}$ Eloisa de Mattos Höfling (2001, p. 31) faz referência a estes dois autores, sem, contudo, indicar a fonte em sua bibliografia. De todo modo, ela conceitua políticas públicas como "o Estado implantando um projeto de governo, através de programas, de ações voltadas para setores específicos da sociedade".

5 A Agenda 2030 do Desenvolvimento Sustentável das Nações Unidas pode ser pesquisada a partir dos portais https://sustainabledevelopment.un.org/post2015/transformingourworld e, em relação ao Brasil, a partir de http://www.agenda2030.com.br/. Acessos em 4 de abril de 2019.

${ }^{6}$ A versão em português da Nova Agenda Urbana está disponível em http://habitat3.org/wp-content/uploads/NUAPortuguese-Brazil.pdf. Acesso em 4 de abril de 2019.

7 Utilizamos, no âmbito do PPGD da PUC-Campinas, o documento que se encontra em https://www.ohchr.org/en/professionalinterest/pages/righttodevelopment.aspx. Acesso em 4 de abril de 2019.
}

Revista de Direito Brasileira | Florianópolis, SC | v. 24 | n. 9 | p.05-18 |Set./Dez. 2019 
Neste sentido, políticas públicas servem -ou devem servir- ao atingimento de todos esses objetivos. Não há dúvida de que direitos são construídos, conquistados, consolidados nessa busca pelos objetivos fundamentais, mas isso acaba ocorrendo de modo indireto e não como objetivo primário da política pública.

$\mathrm{Na}$ busca, por exemplo, pelo desenvolvimento sustentável, até passou-se a falar sobre um direito ao desenvolvimento, mas as políticas públicas criadas para promover crescimento econômico e desenvolvimento socioambiental têm por finalidade este crescimento e este desenvolvimento. A criação, construção ou identificação do direito ao desenvolvimento (ou de quaisquer direitos) decorrem da busca pela finalidade. Ao se promover uma política pública que busque atingir essa finalidade, e na medida em que há desenvolvimento econômico e social, criase um ambiente de promoção de direitos.

Levando em conta o artigo $3^{\circ}$ da Constituição da República de $1988,{ }^{8}$ não existe um direito a uma sociedade livre, justa e solidária (inciso I), embora uma política pública de construção dessa sociedade promova ou melhore nossos direitos, tanto os civis quanto os sociais; não existe um direito ao desenvolvimento nacional (inciso II), mas políticas públicas desenvolvimentistas podem determinar, pela melhoria das condições econômicas, um contexto em que o conteúdo de certos direitos sociais sejam melhor preenchidos; não existe um direito contra a pobreza (inciso III), mas políticas de assistência e de inclusão social podem promover um colchão de garantia econômica que pode ser vista, de modo reflexo, como um direito das pessoas assistidas; e por último, não existe um direito subjetivo à promoção do bem de todos (inciso IV) e, ainda que haja direito individual à não-discriminação de origem, etnia, sexo, idade etc., este direito seria uma condição para realizar uma política pela qual se promova esse bem de todos, e não sua finalidade.

Consideramos que é justamente pelo fato de políticas públicas serem uma atividade estatal baseada em orçamento, isto é, definidas a partir de recursos públicos cujo gasto ou investimento é autorizado para que se implementem as ações que, em tese, atingirão a finalidade prevista (KINGDON, 2014, p. 3), é que elas têm sido tão fortemente relacionadas à promoção dos direitos sociais, econômicos e culturais. Afinal, desde há muito tem-se entendido que estes direitos demandam custos estatais para sua implementação, sendo esta característica a principal distinção em relação aos direitos civis e políticos, que não precisariam de recursos públicos para serem exercidos.

Contudo, essa compreensão dogmática vem sendo combatida desde 1999, quando Stephen Holmes e Cass Sunstein esclareceram, em seu The Cost of Rights, que todo direito, individual ou social, negativo ou a prestações, depende de recursos econômicos e financeiros disponíveis no orçamento para exercício, pelo Estado, de suas funções, sejam estas de prestação de serviço, de exercício de poder de polícia, regulatórias, interventivas ou de fomento. Nesse sentido, sem um Estado que tenha recursos - obtidos em sua maior parte por meio da tributação-, nem as liberdades públicas mais básicas como a liberdade de expressão ou de pensamento podem ser garantidas. Quanto maior a força econômica de um Estado, mais garantias a direitos podem acontecer, o que explica, do ponto de vista daqueles autores, porque há mais direitos em países economicamente mais fortes do que em países em desenvolvimento (HOLMES e SUNSTEIN, 1999). ${ }^{9}$

\footnotetext{
${ }^{8} C f$. o texto da Constituição da República de 1988:

"Art. $3^{\circ}$. Constituem objetivos fundamentais da República Federativa do Brasil:

I - construir uma sociedade livre, justa e solidária;

II - garantir o desenvolvimento nacional;

III - erradicar a pobreza e a marginalização e reduzir as desigualdades sociais e regionais;

IV - promover o bem de todos, sem preconceitos de origem, raça, sexo, cor, idade e quaisquer outras formas de discriminação."

${ }^{9}$ A este respeito, vale mencionar a pesquisa de Mastrodi e Alves (2016), que entenderam acertado o fundamento da teoria dos custos dos direitos, porquanto não pode haver direitos se não houver recursos materiais para sua promoção, porém criticaram a subordinação desses recursos à organização da sociedade de modo a promover, quase que exclusivamente, direitos individuais.
} 
Quanto a este ponto de distinção entre direitos civis "sem custo" e direitos sociais "com custo", ela é problemática, entre outros motivos, porque dá a entender que políticas públicas servem a direitos sociais, e apenas a este tipo (ou dimensão) de direitos. Nesse sentido, há o risco de se entender que políticas públicas seriam o meio mais importante (se não o único) de promover direitos sociais. ${ }^{10}$

No entanto, o que demanda recursos públicos autorizados por lei orçamentária são as ações necessárias ao atingimento de finalidade (ou da consecução de objetivos fundamentais da República, na forma do artigo $3^{\circ}$ de nossa Constituição), de modo que esse custo não caracteriza nem direitos individuais nem direitos sociais, muito menos serve para caracterizar as garantias estatais de preservação desses direitos.

Enfim, o que gera custo são as políticas públicas; o que consome o orçamento são as ações do Estado para atingir os objetivos previamente delineados. Se tal finalidade será atingida, e se, no curso desse programa, direitos forem promovidos, melhorados, garantidos, isso é um resultado direto ou indireto da política pública implementada e não uma qualidade inerente a qualquer direito que tenha sido promovido. Entendemos, assim, inadequado atribuir os custos orçamentários aos direitos que saem protegidos ou melhorados pela implementação da política pública, ponto que será discutido, de modo mais apropriado, na próxima seção.

\section{NÃO HÁ DIREITOS SOCIAIS NO ESTADO LIBERAL, MAS HÁ POLÍTICAS PÚBLICAS}

Políticas públicas é o nome de um campo interdisciplinar do conhecimento e, também, o nome de certo tipo de ação governamental, justamente o objeto de pesquisa daquela ciência interdisciplinar. Seu local de nascimento -tanto o campo de conhecimento quanto seu objeto de pesquisa- são os Estados Unidos da América.

Nasceu em meados do século XX, num país cujo Estado, de modelo marcadamente liberal, não possui nenhuma base que autorize a promoção de direitos sociais, econômicos e culturais.

Se políticas públicas fossem definidas como ações estatais que servem -que funcionampara promover direitos sociais, não haveria como entender as políticas públicas pensadas, criadas e executadas nos EUA como políticas públicas. Ou seja, essa definição é impraticável.

Naquele país, as políticas públicas inicialmente se referiram a ações governamentais pósNew Deal, que recuperaram a então combalida economia dos EUA. Políticas públicas, portanto, tiveram sua gênese na intervenção do Estado na sociedade civil norte-americana.

Os autores que fundaram esse campo do conhecimento sempre trataram de políticas públicas como projetos ou programas que visassem ao restabelecimento de alguma situação que sofreu perdas por causa de alguma grave crise. Restabelecidas as condições originais, superada a crise, encerra-se a atividade governamental prevista para atuar naquela conjuntura.

Jamais houve, na gênese, alguma busca por promover direitos sociais por meio de políticas públicas. Se houve um desastre ambiental, criava-se uma política pública cujo objetivo era restabelecer as condições anteriores, não sendo objeto da discussão saber se direitos seriam devolvidos ao status quo ante: direitos individuais (restabelecimento da boa imagem ou da propriedade das pessoas ou das empresas, por exemplo) e direitos sociais (como restituição das

\footnotetext{
${ }^{10}$ A ideia de que direitos sociais, por terem natureza prestacional e dependerem do orçamento, só podem ser concretizados por meio de ação estatal, em contraposição a direitos individuais, é muito corrente. Como políticas públicas são implementadas apenas mediante autorização orçamentária, não é incomum que autores afirmem que os direitos sociais são executados no âmbito de Estados de bem-estar social por meio de políticas públicas ou ainda, em outras palavras, que os direitos sociais só se efetivam pela execução de políticas públicas. À guisa de exemplo, cf. Carneiro (2018, p. 449) ou Oliveira e Costa (2011, p. 84).
}

Revista de Direito Brasileira | Florianópolis, SC | v. 24 | n. 9 | p.05-18 |Set./Dez. 2019 
condições de moradia ou de acesso a escolas ou hospitais) devem ser, é claro, atendidos, mas de forma colateral, não sendo este o objetivo primordial da política.

Em termos de redução de desigualdades entre pessoas, pode-se entender até mesmo as ações afirmativas ${ }^{11}$ de direitos de personalidade como um tipo de política pública. Programas governamentais que visam a combater o racismo, por exemplo, têm custo de execução, muito embora tratem, em última análise, da promoção de direitos individuais.

O custo envolvido é um dos principais fatores que levam a entender por que toda política pública, para ser compreendida como tal, tem necessariamente que ser idealizada num ciclo com começo, meio e fim, com avaliações periódicas visando a identificar se a aplicação de dinheiro público em certa política deve ou não ser mantida: se os objetivos da política têm sido atingidos, mantém-se a política; do contrário, não se justifica a sua continuidade. Enfim, o custo é característica da política pública, e não do direito que eventualmente seja implementado por ela.

\section{HÁ DIREITOS SOCIAIS NO BRASIL: AS AÇÕES QUE OS PROMOVEM SÃO POLÍTICAS PÚBLICAS?}

No Brasil, o modelo constitucional de Estado é por demais diverso do modelo de Estado dos EUA. Há certos direitos sociais por aqui cuja promoção são dever estatal; por lá, contudo, tais direitos não são sequer considerados ou reconhecidos, quanto mais objetos de alguma garantia.

Ora, políticas públicas, nos EUA, não foram pensadas ou modeladas visando a promover, muito menos a garantir direitos sociais! Por sua característica de programa, pelo qual uma situação qualquer deve ser resolvida até determinado ponto, segundo certos critérios avaliativos definidos na sua própria estruturação normativa, políticas públicas devem sempre ser propostas para terminarem, se não no mesmo exercício financeiro, ao menos dentro do plano plurianual.

Aqui no Brasil, em que o Estado deve promover direitos sociais -por exemplos, direito à saúde, direito à educação ou direito à previdência-, de forma a universalizar tais direitos a todos os cidadãos, as ações de governo para incentivar serviços públicos de saúde, de educação e de previdência não deveriam, jamais, ser descontinuadas. Tais ações, que sem dúvida alguma devem ser planejadas, orientadas para um fim certo e determinado, e avaliadas de modo periódico para eventuais correções de rota, até são chamadas de políticas públicas, mas esta é uma definição brasileira, por demais ampla, diferente da definição original elaborada no contexto em que as políticas públicas foram criadas ou pensadas como ciência ou como ação estatal.

A necessidade e a urgência de promoção de direitos sociais no Brasil, definidas pelo modelo de Estado de bem-estar social constitucionalmente delineado, impõem que ações estatais sejam realizadas nesse sentido, com máxima profundidade e maior alcance possível.

Há, portanto, um dever constitucional de universalização de direitos. Dentro da dogmática constitucional, costuma-se afirmar que os direitos de primeira dimensão prescindem de atuação estatal para sua garantia, por se tratarem de direitos de abstenção por parte do Estado, enquanto os direitos sociais, de segunda dimensão, só seriam promovidos por meio de prestações estatais.

Estas ações estatais têm sido chamadas de políticas públicas, mas talvez segundo aquela noção inicial de "tudo o que o Estado faz". Essa noção, contudo, sofre da mesma falta de precisão atribuída ao direito administrativo no início do século XX, quando toda ação administrativa, fosse o exercício de poder de polícia, fosse de regulação ou de intervenção no mercado ou de fomento público, era entendida como serviço público.

Há, sem dúvida, várias semelhanças entre a ação estatal promovida por meio ou na forma de uma política pública (segundo sua concepção originária) e a ação estatal promovida no Brasil

\footnotetext{
${ }^{11}$ Sobre os aspectos políticos e constitucionais das ações afirmativas no direito dos EUA, cf. Katz (1999). Sobre a produção acadêmica brasileira a respeito do entendimento jurídico das ações afirmativas, cf. Kim e Tommasiello (2018).
}

Revista de Direito Brasileira | Florianópolis, SC | v. 24 | n. 9 | p.05-18 |Set./Dez. 2019 
para a universalização de um direito social. No entanto, há agudas divergências que deveriam determinar distinção entre as duas formas de ação estatal.

A distinção se inicia no comando constitucional. Há dever, previsto pelo poder constituinte originário, de o Estado brasileiro universalizar direitos sociais, de modo ininterrupto e indisponível. Isto não deve ser objeto de negociação na arena da política, isto não é ponto para discussão pelo parlamento; não há nenhuma legitimidade em apresentá-lo como problema a ser resolvido no momento de agenda setting (VIANA, 1996, p. 6; KINGDON, 2014, p. 2-3) de uma política pública. Trata-se de um dever constitucional do Estado.

Se, para Celina Souza (2006, p. 37), política pública "permite distinguir entre o que o governo pretende fazer e o que, de fato, faz", isto denota a capacidade de organização e da definição da agenda sobre o que é relevante no processo democrático entre os poderes Legislativo e Executivo, na definição, por este último, dos temas a serem objeto de deliberação por aquele. Ora, em momento algum, no Brasil, a Constituição autorizou aos mandatários de cargos eletivos que decidam, por exemplo, não promover direitos sociais.

Ademais, nos casos mais emblemáticos, como saúde, educação e previdência social, o dever de implementação de legislação pela qual estes direitos devem ser universalizados e prestados de modo contínuo estão previstos constitucionalmente, não havendo aos poderes constituídos alternativa senão promover e garantir tais direitos sociais que, na forma da legislação baixada por determinação constitucional, trata-se de verdadeiros direitos subjetivos do cidadão, pleiteáveis judicialmente, se necessário, caso haja inércia do administrador público em sua prestação.

Os direitos sociais previstos no artigo $6^{\circ}$ da Constituição da República de 1988 são, ao menos segundo nosso entendimento, garantidos de tal modo pela Constituição que não devem ser retirados do texto constitucional nem mesmo por processo de emenda. A este propósito, e porquanto se trata de assunto candente na política brasileira atual, ressaltamos que não há sentido algum em se discutir uma reforma da previdência sem alteração do texto constitucional.

Qualquer reforma do sistema de previdência brasileiro só possui legitimidade para ser proposta pelos poderes eletivos no campo legislativo, isto é, na forma de prestação desse direito social, sem qualquer possibilidade jurídica de alteração do texto constitucional, haja vista que o dever estatal -universalizante, ininterrupto, indisponível- de prover o direito social à previdência pública encontra-se totalmente protegido pelo que se convencionou definir por cláusula pétrea.

Assim como as ações que promovem direitos sociais, no Brasil, não possuem semelhança com as políticas públicas no seu início, no momento da definição de agenda, também não possuem qualquer semelhança em seu final, na avaliação. ${ }^{12}$ Enquanto toda política pública é avaliada para identificar o atingimento de seu objetivo previamente definido e, assim, interromper a execução das ações estatais, o dever de universalização de direitos sociais impõe ao Estado que tais ações jamais deixem de ser executadas.

Se há dever de avaliação sobre as ações dirigidas a promover direitos sociais, ele não decorre da aplicação da fase final do ciclo de uma política pública, mas do dever de transparência, decorrente do princípio da publicidade previsto no caput do artigo 37 da Constituição da República: toda ação estatal deve ser avaliada para constatar-se a efetiva realização de tal ato segundo seu motivo e para atingimento de sua finalidade, mas sempre para corrigir seu direcionamento, e não para interromper sua prestação. Se direitos sociais dependem da ação do Estado para serem promovidos e protegidos, não faz sentido imaginar qualquer motivo hábil a determinar a cessação do serviço que, não obstante, pode ser alterado ou substituído por outro que, após avaliação, seja identificado como necessário ou mais eficiente.

\footnotetext{
${ }^{12}$ Souza (2006, p. 29) confirma, em sua revisão de literatura sobre políticas públicas, que os estágios que conformam o ciclo deliberativo das políticas públicas são: definição de agenda, identificação de alternativas, avaliação das opções, seleção das opções, implementação e avaliação.
} 


\section{COMPREENSÃO DE POLÍTICAS PÚBLICAS NO DIREITO INTERNO A PARTIR DE SUA COMPREENSÃO NO DIREITO INTERNACIONAL}

Ao se realizar uma política pública, conforme visto anteriormente, procura-se atingir um objetivo e, na medida em que esse objetivo é atingido, direitos acabam sendo construídos, melhorados, mais bem definidos. Com a melhoria das condições de vida decorrente da implementação de uma política pública qualquer, é evidente que, na via reflexa, os direitos das pessoas beneficiadas pela melhoria são implementados. Nesse sentido, políticas públicas não visam a direitos e nem os criam, embora sempre possam melhorá-los.

Para elucidar este ponto cabe, aqui, fazermos referência a uma discussão pertinente que ocorre no âmbito do direito internacional público, qual seja, entender se os direitos humanos (no plano internacional) ou se os direitos fundamentais (no plano interno) devem ser vistos como condições à promoção de políticas públicas ou se estas podem ser implementadas independentemente de atender ou observar quaisquer direitos.

A questão é objeto de debate no ambiente das Nações Unidas, no campo do direito ao desenvolvimento, e das políticas de combate à pobreza. Autores como E. S. Nwauche e J. C. Nwobike (2005), por exemplo, tratam com propriedade a questão, ainda hoje sem solução no direito internacional, sobre implementar programas de desenvolvimento com respeito à proteção aos direitos, ou implementar programas de combate à pobreza levando este objetivo em conta, independentemente de os direitos da população serem respeitados. Isto fica evidente no seguinte excerto:

A redução da pobreza é entendida como o objetivo principal do desenvolvimento, e os direitos humanos são percebidos como meios para atingir tais objetivos ou como princípios a serem seguidos, sem constituírem, por si mesmos, o objetivo do desenvolvimento. Dito de maneira simplificada, o objetivo da assistência ao desenvolvimento é erradicar a pobreza, e não respeitar e promover direitos humanos.

Fica claro, pelo exposto aqui, que a linha divisória entre os contendores acerca da abordagem do desenvolvimento com base nos direitos humanos diz respeito à definição desses direitos. Em outros termos, a promoção e a realização dos direitos humanos deve ser o objetivo fundamental do desenvolvimento, ou tais direitos constituem um meio para atingir o desenvolvimento? (NWAUCHE e NWOBIKE, 2005, p. 100).

Desde a Conferência Mundial sobre os Direitos Humanos de Viena de 1993, houve alguns avanços no âmbito das Nações Unidas sobre a compreensão do direito ao desenvolvimento expresso na Declaração de 1986, consolidando-se o entendimento que este direito seria, nas palavras do alto comissário das Nações Unidas para direitos humanos Rajeev Malhotra (2005), um direito humano universal e inalienável. ${ }^{13}$ Porém, ainda que haja um amplo consenso sobre a natureza do direito ao desenvolvimento, é grande a dissensão quanto a saber se as políticas

\footnotetext{
${ }^{13}$ Declaração das Nações unidas sobre o Direito ao Desenvolvimento de 1986, art. 6º §2 . "Todos os direitos humanos e liberdades fundamentais são indivisíveis e interdependentes; atenção igual e consideração urgente devem ser dadas à implementação, promoção e proteção dos direitos civis, políticos, econômicos, sociais e culturais." Art. $9^{\circ}$, $\S^{\circ}$. "Todos os aspectos do direito ao desenvolvimento estabelecidos na presente Declaração são indivisíveis $e$ interdependentes, e cada um deles deve ser considerado no contexto do todo." Este ponto foi reafirmado pela ONU em 1.993, quando da edição da Declaração e Plano de Ação da Conferência Mundial sobre Direitos Humanos de Viena, em especial na primeira parte de seu art. $5^{\circ}$ : "Todos os direitos humanos são universais, indivisíveis interdependentes e interrelacionados. A comunidade internacional deve tratar os direitos humanos de forma global, justa e equitativa, em pé de igualdade e com a mesma ênfase."
}

Revista de Direito Brasileira | Florianópolis, SC | v. 24 | n. 9 | p.05-18 |Set./Dez. 2019 
internacionais a ele relativas tenham por objeto o desenvolvimento ou o direito ao desenvolvimento.

Tanto que, ao discorrer sobre os seis relatórios sobre direito ao desenvolvimento produzidos pelo expert independente da ONU Arjun Sengupta, fica evidente a questão sobre saber se a promoção desse direito é a grande finalidade das políticas ou se o objetivo principal destas é criar condições econômicas "cujos resultados sejam consistentes com a realização do direito", a ponto de Sengupta ter definido o direito ao desenvolvimento como "o direito a um particular processo de desenvolvimento pelo qual direitos humanos e liberdades fundamentais podem ser plenamente realizáveis" (MALHOTRA, 2005, p. 140).

Ora, há uma diferença conceitual clara entre definir o direito ao desenvolvimento como um direito inalienável composto, de modo indivisível, por direitos individuais e sociais (conforme definição constante da Declaração das Nações Unidas de 1986) a certos direitos e liberdades, e defini-lo como um processo pelo qual serão buscadas as condições sociais adequadas para que tais direitos sejam produzidos. Nas palavras de Sengupta (2003, p. 868):

O direito ao desenvolvimento como o direito a um processo de desenvolvimento não é apenas um direito 'guarda chuva' ou a soma de um arranjo de direitos. Ele é o direito a um processo que expande as capacidades ou liberdades dos indivíduos para melhorar seu bem-estar e realizar o que eles valorizam... O processo não é a mesma coisa que o resultado do processo, embora, no direito ao desenvolvimento, tanto o processo quanto o resultado do processo sejam direitos humanos.

Essa divergência no campo internacional parece refletir, de um lado, a compreensão da doutrina norte-americana sobre políticas públicas, pela qual estas devem servir para atingimento de uma finalidade, mas sem preocupação necessária que essa finalidade sirva para promover direitos (que acabam sendo indiretamente implementados); e de outro, a compreensão de países em desenvolvimento, pela qual a promoção de direitos sociais são vistos como prioritários, verdadeiro motivo pelo qual toda ação estatal deve ser direcionada.

Como os programas internacionais de combate à pobreza ou de promoção do desenvolvimento têm começo, meio e fim, são vistos pelos países centrais como políticas públicas no seu sentido norte-americano; como o combate à pobreza, nos países em desenvolvimento, é visto a partir do fortalecimento dos direitos sociais, há a inversão do entendimento dessas políticas, compreendidas como ações de universalização de direitos.

\section{CONSIDERAÇÕES FINAIS}

Há várias definições possíveis sobre políticas públicas, mas entendemos que estas somente podem ser bem compreendidas se avaliadas a partir de sua função. Nesse sentido, as políticas públicas servem ao propósito de materializar os objetivos do Estado, insculpidos em sua legislação interna ou nos tratados e convenções do qual é signatário, e não de promover direitos sociais. Tanto que Estados de tradição liberal, ainda que descomprometidos com a promoção de direitos, realizam políticas públicas.

Não é possível compreender as ações estatais de prestação de direitos sociais como políticas públicas em sentido estrito. Isto é, se política pública é o nome dado a qualquer ato do Estado ou do governo para se pôr em ação, programas de promoção de direitos sociais poderiam ser afirmados como políticas públicas nesse sentido lato, mas essa definição é tão ampla que permite incluir, aqui (como já dito no início deste artigo), até ações do Estado que organizam sua burocracia interna.

Definições amplas, como se vê, não definem. Elas devem especificar, e não classificar. Nesse sentido, impraticável entender políticas públicas como uma ação estatal qualquer, mas como 
práticas definidas na agenda política dos poderes Legislativo e Executivo visando a consecução de um objetivo público qualquer, porém bem delineado, estabelecido segundo avaliações e comparações da proposta de ação com soluções alternativas tanto no aspecto dos custos quanto dos benefícios envolvidos, assim como nas formas de manter e corrigir as ações implementadas, se bem avaliadas, quanto de interrompê-las, em caso de avaliação negativa.

Para além disso, políticas públicas visam a realizar um objetivo traçado, voltado ao desenvolvimento social ou ao crescimento econômico, previsto na lei de sua criação e cujo custo está autorizado por lei orçamentária. A política pública, por melhor que seja, não é eterna. Ao menos, não era essa a ideia quando originalmente desenvolvida, já que, no contexto social estadounidense, nunca se concebeu a possibilidade de o Estado prover atos em benefício de pessoas por prazo indeterminado e de forma universalizada, sem exigir contrapartidas pela prestação do serviço. Ainda que se possa pensar em promover direitos sociais mediante contrapartidas (como é, por exemplo, o sistema brasileiro de previdência social), direitos sociais devem ser promovidos por meio de ações estatais contínuas, ininterruptas e universalizantes, o que impede que tais ações sejam compreendidas como políticas públicas em sentido estrito.

\section{REFERÊNCIAS}

BOBBIO, Norberto. Da estrutura à função: novos estudos de teoria do direito. Trad. Daniela Beccaccia Versiani. Barueri: Manole, 2007.

BUCCI, Maria Paula Dallari. Políticas públicas e direito administrativo. Revista de Informação Legislativa, a. 34, n. 133, p. 89-98, 1997. Disponível em: <https://www2.senado.leg.br/bdsf/item/id/198 >. Acesso em 21 de agosto de 2019.

CARNEIRO, Débora Ferreira. Do ativismo para o extremismo judicial nas políticas públicas de assistência farmacêutica. Revista de Direito Brasileira, v. 20, n. 8, p. 448-464, 2018. Disponível em: <https://www.indexlaw.org/index.php/rdb/article/view/4390/4009>. Acesso em 21 de agosto de 2019.

COMPARATO, Fábio Konder. Ensaio sobre o juízo de constitucionalidade de políticas públicas. Revista de Informação Legislativa, a. 35 n. 138, 1998, p.39-48, 1998. Disponível em: <https://www2.senado.leg.br/bdsf/handle/id/364>. Acesso em 21 de agosto de 2019.

FREY, Klaus. Políticas públicas: um debate conceitual e reflexões referentes à prática da análise de políticas públicas no Brasil. Planejamento e Políticas Públicas, n. 21, p. 211-259, 2000. Disponível em: <http://www.ipea.gov.br/ppp/index.php/PPP/article/view/89/158>. Acesso em 21 de agosto de 2019.

HÖFLING, Eloisa de Mattos. Estado e Políticas (Públicas) Sociais. Cadernos Cedes, a. 21, n. 55, p. 30-41, 2001. Disponível em: 〈https://dx.doi.org/10.1590/S0101-32622001000300003>. Acesso em 21 de agosto de 2019.

HOLMES, Stephen; SUNSTEIN, Cass. The Cost of Rights: Why Liberty Depends on Taxes. New York: W.W. Norton Company, 1999.

KATZ, Ellis. Political and constitutional aspects of affirmative action in the United States. Revista Jurídica Virtual, v. 1, n. 5, s/p, 1999. Disponível em: 
<https://revistajuridica.presidencia.gov.br/index.php/saj/article/view/1079/1062>. Acesso em 21 de agosto de 2019.

KIM, Richard Pae; TOMMASIELLO, Flávia Carneiro. A produção acadêmica jurídica sobre as ações afirmativas no Brasil (2013 a 2016): teses e dissertações sob a ótica dos direitos humanos e fundamentais. Revista de Direito Brasileira, v. 19, n. 8, p. 276-297, 2018. Disponível em: <https://www.indexlaw.org/index.php/rdb/article/view/3336/3538>. Acesso em 21 de agosto de 2019.

KINGDON, John W. Agendas, Alternatives, and Public Policies: Update Edition, with an Epilogue on Health Care. 2. ed. Harlow: Pearson, 2014.

LEITÃO, André Studart; FREITAS, Brenda Barros; DIAS, Eduardo Rocha. Inclusão excludente, assistência, educação e paternalismo. Revista de Direito Brasileira, v. 17, n. 7, p. 306-327, 2017. Disponível em: <https://www.indexlaw.org/index.php/rdb/article/view/3059/2789>. Acesso em 21 de agosto de 2019.

LÖWI, Theodore J. Four systems of policy, politics and choice. Public Administration Review (impressa), v. 32, n. 4, p. 298-310, 1972.

MALHOTRA, Rajeev. Right to development: where are we today? In SENGUPTA, Arjun et al. Reflections on the Right to Development. Nova Delhi e Londres: Sage, p. 127-152, 2005.

MASTRODI, Josué; ALVES, Abner Duarte. Sobre a teoria dos custos dos direitos. Revista Quaestio Iuris, v. 9, n. 2, p. 695-722, 2016. Disponível em: <https://www.epublicacoes.uerj.br/index.php/quaestioiuris/article/view/19270/16219>. Acesso em 21 de agosto de 2019.

MOURA, Emerson Affonso da Costa. Direitos fundamentais, dever estatal de segurança pública e cidadania: o controle social das políticas. Revista de Direito Brasileira, v. 22, n. 9, p. 4-28, 2019. Disponível em: 〈https://www.indexlaw.org/index.php/rdb/article/view/5148/4266>. Acesso em 21 de agosto de 2019.

NOBRE, Marcos; COSTAS, Judith M.; SUNDFELD, Carlos Ari. O que é pesquisa em Direito? São Paulo: Quartier Latin, 2005.

NWAUCHE, E.S. e NWOBIKE, J.C. Implementação do direito ao desenvolvimento. Trad. Francis Aubert. Sur, Rev Int. Direitos Human., a.2, n.2, 2005, p. 96-117, 2005. Disponível em: <https://dx.doi.org/10.1590/S1806-64452005000100005>. Acesso em 21 de agosto de 2019.

OLIVEIRA, Kátia Cristine Santos de; COSTA. Jamille Coutinho. Direito à Saúde: Da (In)Efetividade das Políticas Públicas à Sua Judicialização Como Forma de Garantir o Mínimo Existencial. Revista de Direito Brasileira, v. 1, n. 1, p. 77-99, 2011. Disponível em: <https://www.indexlaw.org/index.php/rdb/article/view/2678/2572>. Acesso em 21 de agosto de 2019.

PADIN, Camila Ferrara; OLIVEIRA, José do Carmo Veiga de. Análise do programa mais médicos sob o viés constitucional de política pública. Revista de Direito Brasileira, v. 20, n. 8, p. 429-447, 2018. Disponível em: 
<https://www.indexlaw.org/index.php/rdb/article/view/3916/4008>. Acesso em 21 de agosto de 2019.

POMPEU, Gina Vidal Marcílio; CARTAXO, Marina Andrade; CARDOSO, Nardejane Martins. Políticas Públicas, Trabalho e Fronteiras. Revista de Direito Brasileira, v. 8, n. 4, p. 429-447, 2014. Disponível em: 〈https://www.indexlaw.org/index.php/rdb/article/view/2892/2694>. Acesso em 21 de agosto de 2019.

RIBEIRO, Daniela Menengoti. ANJOS, Luiz Sérgio Moreira dos. Desenvolvimento, Políticas Públicas e Direitos Humanos: O Acordo Multilateral de Seguridade Social do Mercosul. Revista de Direito Brasileira, v.1, n.1, p. 291-310, 2011. Disponível em:

<https://www.indexlaw.org/index.php/rdb/article/view/2686/2580>. Acesso em 21 de agosto de 2019.

SENGUPTA, Arjun. On the theory and practice of the Right to Development. Human Rights Quarterly, v. 24, n. 4, p. 837-889, 2002. Acesso restrito em: 〈http://jstor.org>. Acesso em 21 de agosto de 2019.

SOUZA, CELINA. Políticas Públicas: uma revisão da literatura. Sociologias, a. 8, n. 16, p. 2045, 2016. Disponível em: 〈http://dx.doi.org/10.1590/S1517-45222006000200003>. Acesso em 21 de agosto de 2019.

VIANA, Ana Luiza. Abordagens metodológicas em políticas públicas. Revista de Administração Pública (FGV/RJ), v. 30, n 2, p. 5-43, 1996. Disponível em:

<http://bibliotecadigital.fgv.br/ojs/index.php/rap/article/view/8095/6917>. Acesso em $21 \mathrm{de}$ agosto de 2019. 